\title{
Management of Post-Dural Puncture Headache Using Autologous Epidural Blood Patch in a Patient with Acute Lymphoblastic Leukemia
}

\author{
John Narron'1, Mohamed Farrag1, Elbert Mets², Saif Mahmoud'1, Khaled Sedeek ${ }^{1}$ \\ ${ }^{1}$ Hershey Medical Center, Pennsylvania State University, Hershey, PA, USA \\ ${ }^{2}$ Cornell University, Ithaca, NY, USA \\ Email: ksedeek@yahoo.com
}

How to cite this paper: Narron, J., Farrag, M., Mets, E., Mahmoud, S. and Sedeek, K. (2017) Management of Post-Dural Puncture Headache Using Autologous Epidural Blood Patch in a Patient with Acute Lymphoblastic Leukemia. Open Journal of Anesthesiology, 7, 83-87.

https://doi.org/10.4236/ojanes.2017.74008

Received: March 5, 2017

Accepted: April 24, 2017

Published: April 28, 2017

Copyright $\odot 2017$ by authors and Scientific Research Publishing Inc. This work is licensed under the Creative Commons Attribution International License (CC BY 4.0).

http://creativecommons.org/licenses/by/4.0/

\begin{abstract}
We report a case of a patient in remission of acute lymphoblastic leukemia (ALL) with severe positional headaches that required an epidural blood patch (EBP) despite the higher risks of infection and introduction of blast cells to the epidural space. A 43-year-old male with a history of ALL presented with persistent positional headache after multiple intrathecal punctures. Despite initial improvement with medical treatment and bed rest, severe positional headache [consistent with post-dural puncture headache] constantly agonized the patient. EBP was performed after discussion of all of the medical teams involved. Following the procedure, the patient experienced immediate pain relief. EBP is very effective in the management of post-dural puncture headache (PDPH). Still there is risk of introducing infectious and/or malignant cells into the central nervous system. Alternatively, there are agents available that could be employed other than a patient's own blood.
\end{abstract}

\section{Keywords}

Acute Lymphoblastic Leukemia, Intrathecal Punctures, CSF Leakage,

Positional Headaches Epidural Blood Patch, Autologous Blood

\section{Introduction}

Of the complications associated with intrathecal injections, post-dural puncture headache (PDPH) is one of the most common and unpleasant reported. When conventional treatments for PDPH fail, epidural blood patch (EBP) has been shown to be effective. EBP occludes the intrathecal puncture through injection of the patient's own blood into the epidural space. This treatment causes an immediate increase in intrathecal pressure to relieve the patient's headache, and the 
injected blood subsequently halts the CSF leakage from the intrathecal space [1] [2].

Acute lymphoblastic leukemia (ALL) is typically treated using systemic chemotherapy and irradiation [3]. ALL commonly spreads to the central nervous system (CNS), which mandates early diagnosis and CNS prophylaxis, both of which require intrathecal puncture. The multiple intrathecal punctures involved in diagnosis and treatment of ALL place patients at high risk of developing $\mathrm{PDPH}$, and consequently of potential treatment with EBP [4].

A degree of controversy surrounds injecting ALL patients' own blood into the epidural space, and from our recent search, a paucity of data exists regarding the safety of EBP in these patients. In this paper, we report a case in which EBP was performed to successfully alleviate PDPH in a patient with ALL, describe management of a similar case, and conclude with recommendations for treatment and future research.

\section{Case Report}

A 43-year-old, 74-kg male patient, in remission of ALL, with history of multiple intrathecal injections, complained of severe positional headache, which began several hours after his most recent diagnostic spinal puncture. The patient's headache was managed with bed rest, oral and IV fluids, Ibuprofen, and caffeine over a 36-hour period. Despite initial improvement with these treatments, severe positional headache persistently agonized the patient.

In response to the patient's continued discomfort, the pain management team, which comprised an anesthesiologist, neurologist, and oncologist, opted to treat the patient's PDPH using EPB. This procedure is typically benign and effective; though performing EBP for ALL patients presents the risk of introducing circulating blast cells into the patient's CNS as well as higher risk of CNS infection. The patient's most recent cultures were negative for current active infections, which implied minimal risk of infection in this patient with immune system insufficiency. While in remission of ALL, even with an absence of circulating blast cells, we remained concerned about the risk of implanting leukemic cells into the patient's CNS.

Given the patient's lack of active infections and circulating blast cells, J.N performed an EPB under sterile conditions, in which $25 \mathrm{~mL}$ of autologous blood were injected in five-mL increments. The patient's feeling of cerebral fullness and dissipation of headache were used as feedback measures to determine the total volume of blood injected. Following the procedure, the patient reported complete relief of his headache. During his two hours stay before being discharged, there were no other medications given and the patient didn't report suffering from this headache again.

\section{Discussion}

The aim of ALL treatment, including intrathecal chemotherapy, is to induce a state of lasting remission, characterized by the absence of detectable cancer cells 
in the body-defined as less than 5\% blast cells in the bone marrow. The multiple intrathecal punctures required in ALL diagnosis and treatment may be complicated with CSF leakage and persistent incapacitating headache. Several factors affect a patient's likelihood of developing PDPH as a result of intrathecal injection, including the number and technique of the lumbar punctures, the size and type of the needle used, as well as the patient's sex, age, and body habitus.

Initial conservative management of PDPH includes bed rest, IV and oral fluid administration, analgesics, and caffeine. When these therapies fail to assuage headache, other alternatives, although not commonly utilized, include pharmacological treatment with sumatriptan, Desmopressin (DDAVP), Adrenocorticotropic hormone (ACTH), or epidural opioids [1]. Surgery to seal the dural leak may be used as a last resort if PDHP is refractory to other treatment [1]. In addition, sphenopalatine ganglion block has been suggested to treat PDPH [5]. Despite the viability of these treatments, EBP remains the ultimate treatment for $\mathrm{PDPH}$, with demonstrated success rates of up to $90 \%$ following the first attempt [6] [7].

When considering treatment of PDPH for ALL patients, it is imperative to weigh the benefit of headache relief against the patient's heightened risk of infection, and the potential forneuraxial injection with malignant cells. In our case, the team discussed this tradeoff with the patient, whose cultures were negative, who lacked symptoms of infection, and his ALL had been in remission for several months with acceptable hematological indices. Considering the patient's lack of contraindications against EBP, the managing team was confident EBP posed minimal risk above that typically associated with epidural injection. Following EBP, our patient reported alleviation of his headache, and he was discharged from the hospital without complication.

To assess opinions at our institution regarding the safety of using autologous blood to patch ALL patients' dura, six of our regional anesthesiologists completed a questionnaire about the case. Despite the patient's low risk of complication from EBP, two of the six respondents believed it unsafe to inject the patient's own blood intrathecally. They noted concerns about infiltrating the immunocompormised patient's central nervous system with blast cells, as well as the potential for infection chiefly, meningitis.

The literature describing the risk of exposing ALL patients to EBP injections is sparse. In one study, Mergan et al. [8] report a case similar to our own. They described a patient with ALL who presented with severe PDPH two weeks after receiving four rounds of intrathecal methotrexate treatment via serial lumbar puncture. Before treating the patient with EBP, the authors report the patient's negative cerebrospinal fluid and blood cultures revealed no active infections, and flow cytometry indicated an absence of circulating blast cells in the patient's blood. Treatment with EBP using autologous blood improved the patient's symptoms two days following the procedure [8].

Although performed without complication in our case and in that reported by Mergan et al., management of PDHP with autologous EBP may not be appropri- 
ate in patients with active ALL or infections [9]. Performance of EBP with viable alternatives to autologous blood-donated blood, irradiated blood, saline, colloid, and fibrin-is considered to reduce the risk of cancerous spread to the CNS [10] [11].

In conclusion, epidural blood patch (EBP) is effective in the management of post-dural puncture headache (PDPH). Due to the risk of introducing infectious and/or malignant cells into the central nervous system, agents other than a patient's own blood should be used in immunocompromised patients with active infections and/or circulating malignant cells. We recommend the injected fluid used in EBP be selected according to the patients' existing medical condition and infection status. Taken together, the shortage of literature describing the safety of EBP in ALL patients, as well as the severity of the potential complications of injecting autologous blood containing leukemic cells, and of spreading infection intrathecally in this patient population, necessitates further study. Research should be conducted to compare the effectiveness and safety of EBP treatment with autologous blood, to EBP with other agents such as fibrin and donated blood.

\section{References}

[1] Turnbull, D.K. and Shepherd, D.B. (2003) Post-Dural Puncture Headache: Pathogenesis, Prevention and Treatment. British Journal of Anaesthesia, 91, 718-729. https://doi.org/10.1093/bja/aeg231

[2] Cook, M. and Watkins-Pitchford, J.M. (1990) Epidural Blood Patch: A Rapid Coagulation Response. Anesthesia \& Analgesia, 70, 567-568. https://doi.org/10.1213/00000539-199005000-00017

[3] Intermesoli, T., Krishnan, S., MacDougall, F., Jenner, M., Lister, A. and Rohatiner, A. (2011) Efficacy of an Intensive Post-Induction Chemotherapy Regimen for Adult Patients with Philadelphia Chromosome-Negative Acute Lymphoblastic Leukemia, Given Predominantly in the Out-Patient Setting. Annals of Hematology, 90, 10591065. https://doi.org/10.1007/s00277-011-1281-5

[4] Bardon, J., LE Ray, C., Samama, C.M. and Bonnet, M.P. (2016) Risk Factors of Post-Dural Puncture Headache Receiving a Blood Patch in the Obstetric Patients. Minerva Anestesiologica, 82, 641-648.

[5] Cohen, S., Sakr, A., Katyal, S. and Chopra, D. (2009) Sphenopalatine Ganglion Block for Postdural Puncture Headache. Anaesthesia, 64, 574-575. https://doi.org/10.1111/j.1365-2044.2009.05925.x

[6] Sencakova, D., Mokri, B. and McClelland, RL. (2001) The Efficacy of Epidural Blood Patch in Spontaneous CSF Leaks. Neurology, 57, 1921-1923. https://doi.org/10.1212/WNL.57.10.1921

[7] Lay, C.M. (2002) Low Cerebrospinal Fluid Pressure Headache. Current Treatment Options in Neurology, 4, 357-363. https://doi.org/10.1007/s11940-002-0046-9

[8] Mergan, Z.Y., Khetani, N. and Wang, D. (2014) Epidural Blood Patch in Leukemia Patient: A Case Report. Pain Medicine, 15, 1343-1345. https://doi.org/10.1111/pme.12470

[9] Bucklin, B.A., Tinker, J.H. and Smith, C.V. (1999) Clinical Dilemma: A Patient with Postdural Puncture Headache and Acute Leukemia. Anesthesia \& Analgesia, 88, 166-167. 
[10] Abdulla, S., Abdulla, W. and Eckhardt, R. (2011) Caudal Normal Saline Injections for the Treatment of Post-Dural Puncture Headache. Prospective Observational Study. Pain Physician, 14, 271-279.

[11] Chiron, B., Laffon, M., Ferrandière, M. and Pittet, J.F. (2003) Postdural Puncture Headache in a Parturient with Sickle Cell Disease: Use of an Epidural Colloid Patch. Canadian Journal of Anesthesia, 50, 812-814. https://doi.org/10.1007/BF03019377

Submit or recommend next manuscript to SCIRP and we will provide best service for you:

Accepting pre-submission inquiries through Email, Facebook, LinkedIn, Twitter, etc. A wide selection of journals (inclusive of 9 subjects, more than 200 journals)

Providing 24-hour high-quality service

User-friendly online submission system

Fair and swift peer-review system

Efficient typesetting and proofreading procedure

Display of the result of downloads and visits, as well as the number of cited articles

Maximum dissemination of your research work

Submit your manuscript at: http://papersubmission.scirp.org/

Or contact ojanes@scirp.org 